\title{
Anadolu Lisesi Öğrencilerinin Cinsiyet Değişkenine Göre İkinci Yabancı Dil Olarak Almanca Dersinde Bağımsız Öğrenme Düzeyleri
}

Orhan HANBAY*

\section{Özet}

Bu çalışmanın amacı, Anadolu lisesi öğrencilerinin ikinci yabancı dil olarak Almanca dersinde kendi kendine öğrenme düzeylerini cinsiyet değişkenine göre incelemektir. Araştırmanın çalışma grubunu Adıyaman ilindeki üç Anadolu lisesinden $138 \mathrm{klz}$ ve 117 erkek, toplam 255 öğrenci oluşturmaktadır. Veri toplama sürecinde, Hanbay (2010) tarafından geliştirilen "Almanca dersi için kendi kendine öğrenme düzey ölçeği" kullanılmıştır. Elde edilen veriler, bağımsız gruplar t-testi teknığı ile çözümlenmiştir. Araştırmada elde edılen sonuçlar, öğrencilerin puan ortalamaları arasında kız öğrencilerin lehine istatistiksel açıdan anlamlı bir farkın olduğunu göstermiştir.

Anahtar Kelimeler: Çok dillilik, ikinci yabancı dil olarak Almanca, kendi kendine öğrenme.

\section{The Autonomous Learning Level of the Anatolian High School Students in the German as a Second Foreign Language}

\section{Abstract}

The aim of this study is to investigate the autonomous learning level of the Anatolian high school students in the German as a second foreign language course after the variable gender. The study group consisted of 138 girls and 117 boys total of 255 students in three Anatolian high schools in the province of Adiyaman (Turkey). During the data collection was used "The autonomous learning level scale for German lessons", developed by Hanbay (2010). The data obtained were analyzed by independent samples t-test technique. The results obtained in this study, the mean scores of students in favor of female students showed a statistically significant difference.

Key words: Multilingualism, German as a second foreign language, autonomous learning.

\footnotetext{
*Yrd. Doç. Dr., Adıyaman Üniversitesi, Kahta Meslek Yüksekokulu
} 


\section{Giriş}

Küreselleşmenin hızla ilerlediği bu çağda, yabancı dile duyulan gereksinim öncesine göre daha da artmıştır. Artık Avrupa'daki birçok öğrenci, yalnız bir yabancı dil öğrenmeyle yetinmemektedir. Bu nedenle son zamanlarda birden fazla yabancı dilin etkili bir şekilde öğrenilebilmesi ve öğretilebilmesi ile ilgili olarak kapsamlı tartışmalar yapılmaktadır (Koithan 2001: 3). Bu tartışmalardan çıkan sonuçlardan biri, okul programlarına ardı ardına farklı dillerin öğretileceği derslerin konulmasıdır (Neuner ve Hufeisen 2001: 18). Ancak, ikinci ya da sonraki yabancı dilin öğrenme ve öğretme koşulları birinci yabancı dil dersindekinden farklıdır.

İkinci yabancı dil dersi denildiğinde, daha önceden okul ortamında birinci yabancı dili öğrenmiş (4. ya da 5. sınıflardan başlayarak), belli bir soyutlama çağına ulaşmış (14 ile 16 yaş) öğrencilere, önbilgilerini sürekli etkin kılmak koşuluyla ikinci yabancı dili öğretmek anlaşılmalıdır (Neuner ve Hufeisen 2001: 31-34). Aşağıdaki tabloda birinci ve ikinci yabancı dil derslerinin öğrenme koşulları karşılaştırmalı olarak yer almaktadır:

Tablo 1: Birinci ve İkinci Yabancı Dil Derslerinin Karşılaştırılması

\begin{tabular}{ll}
\hline Birinci Yabancı Dil Dersi & İkinci Yabancı Dil Dersi \\
\hline Yaş (10-11) & Yaş (15-16) \\
Somut işlemler dönemi & Soyut işlemler dönemi \\
Yabancı dile ilişkin dekleratif & Yabancı dile ilişkin dekleratif \\
bilgi yok & bilgi var \\
Yabancı dile ilişkin & Yabancı dile iliş̧kin prosedürel \\
prosedürel bilgi yok & bilgi var \\
\hline
\end{tabular}

(Koithan 2001: 3-4)

İkinci yabancı dil dersine ayrılan süre, gerek haftalık ders saati gerekse yıllara göre dağılım açısından, birinci yabancı dil dersine göre oldukça kısıtlıdır. Buna karşın ikinci yabancı dil derinden birincide olduğu kadar başarı hedeflenir. Söz konusu başarının elde edlilmesi, daha etkili, ekonomik bir ders izlencesine bağlıdır. Daha ekonomik öğrenme ve öğretme yöntemlerinin oluşturulması, öğrenenlerin yukarıdaki paragrafta belirtilen önbilgilerinin, bir başka deyişle onların öğrenme deneyimleri ve dilsel önbilgilerinin işe koşulmasına bağlıdır. Bu amaçla ikinci yabancı dil dersinde aşağıda belirtilen iki unsurdan özellikle yararlanmak gerekir: 
- Dekleratif bilgi (birinci yabancı dil ve anadilinden kaynaklı dilsel bilgilerin kullanımı)

- Prosedürel bilgi (birinci yabancı dili öğrenirken edinilen öğrenme yöntem ve teknik bilgisi) (Neuner ve Hufeisen 2001: 160)

Dekleratıf ve prosedürel bilgilerin ders içerisinde öğrenciler tarafından etkin bir iekilde kullanılması, Almancayı öğrenme sürecinin yalnız ders içinde değil, ders dışında da sürmesine olanak sağlayabilir. Bunun nedeni, sözü edilen becerilerin geliştirilmesiyle öğrencilerin hem Almancayı öğrenme süreci hem de önbilgilerini kullanma konusunda deneyim kazanarak kendi kendine öğrenme aşamasına gelebilecekleri gerçeğidir. Bu da sözü edilen ikinci yabancı dil olarak Almanca dersindeki süre kısıstlığına bir çözüm olarak düşünülebilir. Çünkü bu yolla bir yandan ders verimli bir şekilde geçecek, diğer yandan da öğrenciler Almancayı ders dışında da öğrenebileceklerdir.

Peki dekleratıf ve prosedürel bilginin derste öğrenciler tarafından kullanılması onların Almancayı kendi kendine öğrenme becerilerini geliştirebilir mi? Yıldırım (2004: 142) bu konuyla ilgili olarak öğrenmenin en üst düzeyi olan yansıtmadan söz etmektedir ve yaşam boyu öğrenme (dolayısıyla kendi kendine öğrenme)'nin buna dayandığını belirtir. Ona göre yansıtma mantıksal becerilerden farklı değildir; öğrenilebilir ve geliştirilebilir. Almanca dersi için düşünüldüğünde, yeni dilsel içeriklerin aktarılmasının yanında var olan dilsel bilgilere ilişkin dekleratif bilginin (önbilgiler) yansıtılması önemlidir. Bununla, derste sürekli olarak Almanca, İngilizce ve Türkçeye ilişkin dilsel unsurların bilinçli bir şekilde birbirleriyle karşılaştııılarak ele alınması anlaşılmalıdır. Bu yolla öğrenciler, diller arasındaki benzerliklerin yanında farklılıkları da görüp öğrenmelerini daha da verimli hale getirebileceklerdir (Neuner ve Hufeisen 2001: 182). Bununla birlikte derste prosedürel bilgilerin de öğrenciler tarafından etkin olarak kullanılmasının sağlanması önemli bir unsurdur.

Böylece ders ortaminda gerek dekleratıf gerekse prosedürel bilgilerin kullanılması konudunda belli bir düzeye gelen öğrencilerin okul dışında da bu becerilerini kullanarak Almancayı kendi kendilerine öğrenebilecekleri düşünülebilir.

\section{Araştırmanın Amacı}

$\mathrm{Bu}$ araştırmanın amacı, yukarıda belirtilen bilgiler ışığında öğrencilerin (cinsiyet faktörü gözetılerek) ikinci yabancı dil olarak 
Uşak Üniversitesi Sosyal Bilimler Dergisi

$2013,6 / 4$

O. HANBAY

Almancayı öğrenmede kendi kendine öğrenme düzeylerini belirlemektir. Bu amaçla aşağıdaki araştırma sorularına yanıtlar aranmıştır:

- Öğrencilerin cinsiyetlerine göre Almancayı kendi kendine öğrrenme düzeyleri arasında genel olarak bir fark var mıdır?

- Öğrencilerin cinsiyetlerine göre Almancayı kendi kendine öğrrenme düzeyleri arasında alt boyutlara göre bir fark var midir?

\section{Yöntem}

Anadolu lisesi öğrencilerinin ikinci yabancı dil olarak Almanca dersi kapsamında kendi kendine öğrenme düzeylerinin incelendiği bu çalışmada tarama modeli kullanılmıştır.

\section{Çalışma Grubu}

Araştırmanın çalışma grubunu Adıyaman ilindeki üç Anadolu lisesinden yansız atamayla seçilen toplam 255 öğrenci oluşturmaktadır. Öğrencilerin cinsiyet değişkenine göre dağılımları aşağıdaki gibidir:

Tablo 2: Örneklemi Oluşturan Öğrencilerin Cinsiyet Değişkenine Göre Dă̆gllımları

\begin{tabular}{lll}
\hline Cinsiyet & $f$ & $\%$ \\
\hline Kiz & 138 & 54,1 \\
Erkek & 117 & 45,9 \\
Toplam & 255 & 100 \\
Toplam & 217 & 100 \\
\hline
\end{tabular}

\section{Veri Toplama Araçları}

Veriler, Hanbay (2010) tarafından geliştirilen "İkinci yabancı dil olarak Almanca dersine yönelik kendi kendine öğrenme ölçeği" ile 20112012 eğitim-öğretim yılında toplanmıştır. 5'li Likert tipi ölçeğin maddeleri ile bunların faktör yükleriyle tümünün faktör analizi sonuçları aşağıdaki gibidir:

Tablo 3: Kendi Kendine Öğrenme Düzey Ölçeğginin Maddeleri ve Faktör Yükleri 
Uşak Üniversitesi Sosyal Bilimler Dergisi

$2013,6 / 4$

O. HANBAY

Yansitma

Faktör yükü

İngilizcedeki bilgilerim Almanca çalışırken işimi

kolaylaştırıyor.

Almanca dersinde karşılaştığım bir güçlük olursa,

İngilizce bilgilerimden yararlanıorum.

Güdülenmişlik

Almanca öğrenmeyi gereksiz buluyorum.

Almanca dersinde daha fazla şey öğrenmeyi istiyorum.

Yabancı dil dersleri geleceğim için oldukça gereklidir.

Almanca dersinde öğrendiklerimi ileride kullanabileceğimi

düşünmüyorum.

Akranlarıyla işbirliği

Almanca dersinde öğrendiklerimi arkadaşlarımla

paylaşıyorum.

Almanca dersinde anlamadıklarımı arkadaşlarıma sormam. $(0,75)$

Almanca dersinde yardımlaşacağım arkadaşım yok.

Almanca dersinde verilen işleri arkadaşlarımla yardımlaşarak yaparım.

Zaman Yönetimi

Almanca çalışmak için gerekli zamanı bulamıyorum. $\quad(0,85)$

Yeterince zaman bulamadığım için derslerime

çalışamiyorum.

Diğer derslerim yüzünden Almancayla uğraşacak zamanı

ulamiyorum.

(Hanbay 2010: 565-566)

Bir sonraki tabloda ölçeğin tümüne ilişkin faktör analizine yer verilmiştir:

Tablo 4: Kendi Kendine Öğrenme Ölçeği KMO ve Bartlett testi sonuçları

\begin{tabular}{cl}
\hline $\mathrm{KMO}=$ & 0,617 \\
Bartlett Test & \\
\hline Approx. Chi-Square & 268,352 \\
df & 78 \\
Sig & 000 \\
\hline
\end{tabular}

KMO ve Bartlett testi faktör analizinin uygunluğunu test eder (Tavşancıl 2006, 206). Başka bir deyişle, değişkenlerin faktör analizine alınıp 
Uşak Üniversitesi Sosyal Bilimler Dergisi

$2013,6 / 4$

O. HANBAY

alınamayacağı konusunda fikir verir. KMO'nun 0,60'dan yüksek olması Bartlett'in anlamlı olduğunu göstermektedir (Büyüköztürk 2004, 120). Ölçeğin güvenirlik analizi sonuçları Tablo 5'te verilmiştir:

Tablo 5: Kendi Kendine Öğrenme Ölçeğinin Güvenirlik Çözümlemesi Sonuçları

\begin{tabular}{|c|c|c|c|c|}
\hline & $\begin{array}{l}\text { Yan- } \\
\text { sitma }\end{array}$ & $\begin{array}{l}\text { Güdülen- } \\
\text { mişlik }\end{array}$ & $\begin{array}{l}\text { Akranlarla } \\
\text { İşbirliği }\end{array}$ & $\begin{array}{l}\text { Zaman } \\
\text { Yönetimi Tümü }\end{array}$ \\
\hline \multicolumn{5}{|l|}{ Geçerli } \\
\hline Madde Sayısı & 2 & 4 & 4 & 13 \\
\hline Cronbach Alpha & 71 & ,72 & ,72 & 749 \\
\hline
\end{tabular}

Cronbach alpha iç tutarlılık katsayısının ,70'in üzerinde olması güvenirlik için yeterlidir (Bayram 2004: 128). Yukarıdaki değerlere bakıldığında faktörlerin tümünün ,70'in üzerinde olduğu görülmektedir. Dolayısıyla ölçeğin bu haliyle kullanılabileceği söylenebilir.

\section{Verilerin Çözümlenmesi}

Anadolu lisesi öğrencilerinin ikinci yabancı dil olarak Almanca dersinde kendi kendine öğrenme düzeylerinin belirlenmesi amacıyla yapılan bu çalışmada elde edilen veriler, bağımsız gruplar t-testi kullanılarak istatistiksel veri analizi ile \%95'lik anlamlılık düzeyinde çözümlenmiştir. Puan ortalamalarına verilen değerler 3,5-5 arası yüksek, 2,53,4 orta ve 1,0-2,4 düşük şeklindedir (Wharton 2000, 215).

\section{Bulgular}

İkinci yabancı dil olarak Almanca dersinde kız ve erkek öğrencilerin kendi kendine öğrenme becerilerinin saptanmaya çalışıldığı araştırmanın bu bölümünde elde edilen bulgulara yer verilmiştir:

\section{1 Öğrencilerin cinsiyetlerine göre Almancayı kendi kendine} öğrrenme düzeyleri arasında genel olarak bir fark var mıdır?

İstatistiksel çözümlemelerden gruplar arası t-testi kullanılarak elde edilen bulgular aşağıdaki gibidir:

İlk olarak ölçeğin bir bütün olarak ne şekilde yansıdığını görmek amacıyla bütün boyutların ortalamalarına ilişkin bulgulara yer verilmiştir: 
Uşak Üniversitesi Sosyal Bilimler Dergisi

Tablo 6: Kendi Kendine Öğrenme Düzey Ölçeği T-testi Sonuçlarn

\begin{tabular}{lllllll}
\hline Gruplar & $\mathrm{N}$ & $\mathrm{X}$ & $\mathrm{S}$ & $\mathrm{t}$ & $\mathrm{df}$ & $\mathrm{p}$ \\
\hline Kiz & 138 & 3,39 &, 69 & 2,802 & 233,9 &, 006 \\
Erkek & 117 & 3,13 &, 78 & & & \\
\hline
\end{tabular}

Tablo 6 incelendiğinde, genel olarak kendi kendine öğrenme düzeyi ile ilgili kız ve erkek öğrenciler arasında kız öğrencilerin lehine istatistiksel açıdan anlamlı bir $(t=2,802 ; \mathrm{p}<, 05)$ farkın olduğu görülmektedir.

Öğrencilerin ikinci yabancı dil olarak Almanca dersinde kendi kendine öğrenme becerisi konusunda ölçeğin bütünü ele alındığında kız öğrencilerin lehine görünen bu durumun alt boyutlara bakarak daha ayrıntılı bir şekilde irdelenmesi yerinde olacaktır. Alt boyutlara ilişkin bulgular aşağıdaki gibidir:

\section{2 Öğrencilerin cinsiyetlerine göre Almancayı kendi kendine} öğrrenme düzeyleri arasındaki alt boyutlara göre bir fark var mıdır?

\section{Birinci Yabancı Dilden Yararlanma Düzeyi (Yansıtma)}

Öğrencilerin cinsiyetlerine göre ikinci yabancı dil olarak Almancayı öğrenirken birinci yabancı dilden (İngilizce) yararlanma düzeyleri ile ilgili puan ortalamaları tablo 6 'da yer almaktadır.

Tablo 7: Birinci Yabancı Dilden Yararlanma Düzeyine İlişkin T-Testi Sonuçları

\begin{tabular}{lllllll}
\hline Gruplar & $\mathrm{N}$ & $\mathrm{X}$ & $\mathrm{S}$ & $\mathrm{t}$ & $\mathrm{df}$ & $\mathrm{p}$ \\
\hline Kiz & 138 & 3,5 & 1,03 & 3,621 & 234,3 &, 000 \\
Erkek & 117 & 3 & 1,17 & & & \\
\hline
\end{tabular}

Tablo 7'deki verilere bakıldığında, kız öğrencilerin ikinci yabancı dil olarak Almancayı öğrenirken birinci yabancı dilden yararlanma düzeylerinin erkek öğrencilere göre daha yüksek olduğu görülmüştür. Bununla birlikte puan ortalamalarının istatistiksel açıdan anlamlı düzeyde $(t=3,621 ; p<, 05)$ farklılaştığı görülmektedir.

\section{Güdülenme Düzeyi}

Öğrencilerin ikinci yabancı dil olarak Almanca dersindeki güdülenme düzeyleri ile ilgili t-testi sonuçları tablo 7'de gösterilmiştir: 
Uşak Üniversitesi Sosyal Bilimler Dergisi

Tablo 8: Güdülenme Düzeyi ile İlgili T-testi Sonuçları

\begin{tabular}{lllllll}
\hline Gruplar & $\mathrm{N}$ & $\mathrm{X}$ & $\mathrm{S}$ & $\mathrm{t}$ & $\mathrm{df}$ & $\mathrm{p}$ \\
\hline Kiz 138 & 3,78 &, 89 & 2,210 & 235,6 &, 028 & \\
Erkek & 117 & 3,52 &, 99 & & & \\
\hline
\end{tabular}

Tablo 8 incelendiğinde öğrencilerin ikinci yabancı dil olarak Almanca dersindeki güdülenmişlik düzey puan ortalamalarının kız öğrencilerin lehine istatistiksel açıdan anlamlı bir farkın $(t=2,210, p<, 05)$ olduğu görülmüştür.

\section{Akranlarıyla İşbirliği Düzeyi}

Öğrencilerin ikinci yabancı dil olarak Almancayı öğrenirken akranlarıyla işbirliği yapma düzeyleri ile ilgili puan ortalamalarının karşılaştırıldığı t-testi sonuçları tablo 8'de yer almaktadır.

Tablo 9: Akranlarıyla İşbirliği Düzeyine İlişkin T-testi Sonuçları

\begin{tabular}{lllllll}
\hline Gruplar & $\mathrm{N}$ & $\mathrm{X}$ & $\mathrm{S}$ & $\mathrm{t}$ & $\mathrm{df}$ & $\mathrm{p}$ \\
\hline K1z & 138 & 3,45 & 1 & 1,301 & 241 &, 194 \\
Erkek & 117 & 3,28 & 1,05 & & & \\
\hline
\end{tabular}

Tablo 9'daki veriler incelendiğinde akranlarıyla işbirliği yapma konusunda kız ve erkek öğrencilerin puan ortalamaları arasındaki farkın istatistiksel açıdan anlamlı olmadığ $(t=1,301 ; p>, 05)$ görülmektedir.

\section{Zamanı Etkili Kullanma Düzeyi}

Öğrencilerin ikinci yabancı dil olarak Almancayı öğrenirken zamanı etkili kullanma düzeyleri ile ilgili puan ortalamalarına ilişkin karşılaştırmanın yer aldığı veriler tablo $9^{\prime}$ da bulunmaktadır.

Tablo 10: Zamanı Etkili Kullanma ile İlgili T-testi Sonuçları

\begin{tabular}{|c|c|c|c|c|c|c|c|}
\hline Gruplar & $\mathrm{N}$ & $x$ & & $S$ & & $\mathrm{t}$ & $\mathrm{df}$ \\
\hline Kız 138 & 2,72 & & 1,19 & & 1,432 & 247 & 153 \\
\hline Erkek & 117 & 2,50 & & 1,18 & & & \\
\hline
\end{tabular}

Tablo 10'a bakıldığında, bu alt boyutta da kız ve erkek öğrencilerin puan ortalamaları arasında istatistiksel açıdan herhangi bir farkın bulunmadığı $(\mathrm{t}=1,432 ; \mathrm{p}>, 05)$ anlaşılmaktadır. 


\section{Sonuç ve Öneriler}

Ölçeğin bütününe bakıldığında kız ve erkek öğrencilerin puan ortalamalarının orta düzeyde (kızlar 3,39; erkekler 3,13) olduğu anlaşılmaktadır. Alt boyutlardaysa yalnız "güdülenme" faktöründe yüksek düzeyde bir puan ortalaması (kızlar 3,78; erkekler 3,52) saptanmıştır. En düşük puan ortalamalarının ise "zaman yönetimi" alt boyutunda olması ((kızlar 2,72; erkekler 2,50) göze çarpmaktadır.

Öğrencilerin ikinci yabancı dil olarak Almancayı öğrenirken kısıtlı ders saati nedeniyle ders dişında kendi öğrenmelerini gerçekleştirmeleri durumunda daha iyi öğrenme sonuçlarının alınacağı düşünüldüğünde orta düzeydeki bu sonuçlar, öğrencilerin derste gerek dekleratif gerekse prosedürel bilgilerinin işe koşulması konsusunda daha fazla özen gösterilmesinin gerekliliğini ortaya koymaktadır.

Özellikle zaman yönetimi konusunun yalnız Almanca dersi için değil, öğrencilerin yaşamlarının genelinde ne denli önemli olduğu düşünüldüğünde, tek başına bu konunun bile özenle ele alınması durumunda, öğrencilerden beklenen başarının ne denli değilebileceği anlaşılabilir.

Diğer bir açıdan bakılacak olursa, prosedürel ve dekleratif bilgilerin derste işe koşulması ile kendi kendine öğrenme arasındaki ilişkinin inceleneceği başka bir çalışma da önerilebilir. Bu yolla yerel düzeyde durumun somutlaştırılması ve çözüm önerilerinin daha somut hale getirilmesi sağlanabilir.

\section{Kaynakça}

Bayram, N. (2004). Sosyal bilimlerde SPSS ile veri analizi, Bursa: Ezgi Kitabevi

Büyüköztürk, Ş. (2004). Sosyal bilimler için veri analizi el kitabı (4. Basım), Ankara: Pegem A Yaincılık

Hanbay, O. (2010). İkinci yabancı dil olarak Almanca dersine yönelik kendi kendine öğrenme ölçeği 1 10. Uluslararası Dil, Yazın ve Deyişbilim Sempozyumu, Ankara: Gazi Üniversitesi Gazi Eğitim Fakültesi, Yabancı Diller Eğitimi Bölümü.

Koithan, U. (2001). Tertiärsprachen lehren und lernen Beispiele Deutsch nach Englisch (Teil 5,5). Mehrsprachigkeit im Anfansunterricht. Kassel. 
Uşak Üniversitesi Sosyal Bilimler Dergisi

$2013,6 / 4$

O. HANBAY

Neuner, G. ve Hufeisen, B. (2001). Mehrsprachigkeit und Tertiärsprachenlernen Erprobungsfassung). Kassel

Tavşancıl, Ezel (2006). Tutumların Ölçülmesi ve SPSS ile Veri Analizi (3. Baskı), Ankara: Nobel Yayıncilık.

Wharton, Glenn (2000). Language learning strategy use of bilingual foreign language learners in Singapore. Language Learning 50: (2), 203-243.

Yıldırım, R. (2004), Öğrenmeyi öğrenmek, Ankara: Sistem Yayıncılık. 